\title{
EFEKTIVITAS MODEL DISCOVERY LEARNING DITINJAU DARI PEMAHAMAN KONSEP MATEMTIS SISWA KELAS XI IPS SMA NEGERI 1 GAMPING
}

\author{
Khamidah, Kristina Warniasih \\ Jurusan Pendidikan Matematika, Universitas PGRI Yogyakarta \\ Jl. PGRI 1 Sonosewu No. 117 Yogyakarta - 55182 Telp/Fax. (0274) 376808 \\ E-mail:khamidahchans@gmail.com,kristinawarniasih@yahoo.com
}

\begin{abstract}
.
One of the goals of mathematics learning is that students are expected to have good understanding mathematics concept abilities. The application of discovery learning model in the process of learning mathematics is one of the learning modelsthat can improve students understanding of mathematics concepts. The learning process uses the discovey learning model so that students can find the concepts of the material being studied and can conclude their own concepts that have been found based on their ability to understand. This research aims to determine that: (1) students understand the mathematics concepts of discovery learning model in effective;(2) students understand the mathematics concepts of conventional learning model in effevtive; (3) the effectiveness of discovery learning model and conventional learning for understanding mathematics concepts, and to know in $11^{\text {th }}$ Senior High School at SMA N 1 Gamping. This type of research is an experimental quasi experiment with research design Posttest Only Control Design. The population in this study were students of class XI IPS SMA N 1 Gamping. The sample in this study was class XI IPS 1 as an experimental class and class XI IPS 2 as a control class. The instrument used in the study was the observation sheet of the implementation of learning and the students understanding mathematics concepts test questions. Analysis of the data used is the t-test and the prerequisite test used are normality and homogeneity test. The result showed that using discovery learning model and conventional learning model were effective that students understand the mathematics concepts, and learning using discovery learning model was more effective than conventional learning model when viewed from students understand the mathematics concepts.
\end{abstract}

Keywords: Discovery Learning Model, Conventional Learning Model, understanding mathematics concept.

\begin{abstract}
Abstrak.
Salah satu tujuan dari pembelajaran matematika adalah siswa diharapkan memiliki kemampuan pemahaman konsep matematis yang baik. Penerapan model discovery learning dalam proses pembelajaran matematika merupakan salah satu model pembelajaran yang dapat meningkatkan pemahaman konsep matematis siswa. Proses pembelajaran menggunakan model discovery learning bertujuan agar siswa dapat menemukan konsep materi yang dipelajari dan dapat menyimpulkan sendiri konsep yang sudah ditemukan berdasarkan kemampuan pemahamannya. Penelitian ini bertujuan untuk mengetahui: (1) model discovery learniing efektif digunakan dalam pembelajaran bila ditinjau dari pemahaman konsep matematis siswa kelas XI IPS SMA Negeri 1 Gamping; (2) model pembelajaran konvensional efektif digunakan dalam pembelajaran bila ditinjau dari pemahaman konsep matematis siswa kelas XI IPS SMA Negeri 1 Gamping; (3) model discovery learning lebih efektif digunakan dalam pembelajaran dibandingkan dengan model pembelajaran konvensional bila ditinjau dari pemahaman konsep matematis siswa kelas XI IPS SMA Negeri 1 Gamping. Jenis penelitian ini adalah eksperimen dengan bentuk quasi experiment dengan desain penelitian Posttest Only Control Design. Populasi dalam penelitian ini adalah siswa kelas XI IPS SMA Negeri 1 Gamping. Sampel dalam penelitian ini adalah kelas XI IPS 1 sebagai kelas eksperimen dan kelas XI IPS 2 sebagai kelas kontrol. Instrumen yang digunakan dalam penelitian adalah lembar observasi keterlaksanaan pembelajaran dan soal tes pemahaman konsep matematis siswa. Analisis data yang digunakan adalah uji-t dan uji prasyaratnya yang digunakan adalah uji normalitas dan homogenitas. Hasil penelitian menunjukkan dengan menggunakan model discovery learning dan model pembelajaran konvensional efektif terhadap pemahaman konsep matematis siswa, dan pembelajaran dengan menggunakan model discovery learning lebih efektif dibandingkan dengan model pembelajaran konvensional bila ditinjau dari pemahaman konsep matematis siswa.
\end{abstract}

Kata Kunci: Model Discovery Learning, Model Pembelajaran Konvensional, Pemahaman Konsep Matematis 


\section{PENDAHULUAN}

Pemahaman konsep sangat penting karena dengan penguasaan konsep akan memudahkan siswa dalam mempelajari matematika. Pada setiap pembelajaran matematika diusahakan lebih ditekankan pada penguasaan konsep agar siswa memiliki bekal dasar yang baik untuk mencapai kemampuan dasar yang lain seperti penalaran, komunikasi, koneksi, dan pemecahan masalah. Sesuai dengan Cahyo (2013: 241) bahwa mata pelajaran matematika menekankan pada konsep, artinya dalam mempelajari matematika siswa harus memahami konsep matematis terlebih dahulu agar dapat menyelesaikan soal-soal dan mampu mengaplikasikan pembelajaran tersebut di dunia nyata. Konsep-konsep dalam matematika terorganisasikan secara sistematis, logis, dan hierarkis dari yang paling sederhana ke yang paling kompleks.

Salah satu materi yang menerapkan pemahaman konsep matematis di tingkat SMA yaitu aljabar. Dari persentase daya serap matematika tahun pelajaran 2016/2017 menunjukan rata-rata nilai UN untuk jurusan IPS masih kurang dari 50\%. Untuk persentase daya serap materi aljabar di tingkat sekolah SMA Negeri 1 Gamping mencapai 53,52\%, walaupun persentasenya lebih tinggi dibandingkan dengan daya serap di tingkat kota/kabupaten, pemahaman konsep matematis di SMA Negeri 1 Gamping masih perlu dioptimalkan kembali.

Dalam proses kegiatan belajar mengajar di sekolah tentunya diperlukan model pembelajaran yang dapat membantu menciptakan, mengembangkan, bahkan meningkatkan kemampuan-kemampuan yang harus dimiliki oleh siswa. Model yang digunakan tentunya harus tepat dengan keterlibatan siswa di kelas, dengan tujuan agar siswa lebih aktif dalam mengikuti proses belajar mengajar. Oleh karena itu, sebelum melakukan pembelajaran di kelas, seorang guru harus merancang terlebih dahulu perangkat pembelajaran yang akan dilakukan dengan tujuan agar dapat memunculkan keaktifan siswa dalam memahami konsep. Salah satu model pembelajaran yang dinilai tepat dalam meningkatkan pemahaman konsep matematis siswa adalah model Discovery Learning.

Berdasarkan uraian di atas, perlu diadakannya penelitian untuk mengetahui Efektivitas Model Discovery Learning ditinjau dari Pemahaman Konsep Matematis Siswa Kelas X IPS SMA Negeri 1 Gamping tahun ajaran 2019/2020.

\section{LANDASAN TEORI}

\subsection{Efektivitas}


Efektivitas pembelajaran adalah ukuran keberhasilan dari suatu kegiatan belajar mengajar dengan strategi yang telah dirancang agar mencapai tujuan pembelajaran. Dalam penelitian ini, efektivitas pembelajaran dilihat dari pencapaian tujuan pembelajaran yang terkait dengan pemahaman konsep matematis siswa, yaitu apabila peningkatan pemahaman konsep matematis siswa pada kelas yang menggunakan model discovery learning lebih tinggi dari pada siswa pada kelas yang menggunakan pembelajaran konvensional.

\subsection{Model Pembelajaran}

Model pembelajaran adalah kerangka konseptual yang digunakan sebagai pedoman dalam pembelajaran untuk mencapai tujuan tertentu.

\subsection{Discovery Learning}

Discovery Learning adalah model pembelajaran yang memberikan peluang kepada siswa untuk aktif dalam menemukan konsep materi yang sedang dipelajarinya secara mandiri maupun kelompok dengan bimbingan guru.

Sintaks model discovery learning menurut Hosnan (2014: 289):

a. Stimulastion (stimulasi/ pemberian rangsangan)

Pada tahap ini, siswa dihadapkan pada suatu permasalahan, kemudian dilanjutkan untuk tidak memberikan generalisasi, agar timbul keinginan untuk menyelidiki permasalahan tersebut. Selain dengan menghadapkan pada suatu masalah, guru juga dapat memulai pembelajaran dengan mengajukan pertanyaan, anjuran membaca buku, dan aktivitas lainnya yang mengarahkan siswa pada persiapan pemecahan masalah.

b. Problem Statement (pernyataan/ identifikasi masalah)

Pada tahap ini, guru memberikan kesempatan kepada siswa untuk mengidentifikasi sebanyak mungkin informasi yang relevan dengan bahan pelajaran. Kemudian salah satunya dipilih dan dirumuskan dalam jawaban sementara atas pertanyaan masalah.

c. Data Collection (pengumpulan data)

Pada tahap ini, siswa mengumpulkan berbagai informasi yang relevan, membaca literatur, mengamati objek, atau melakukan uji coba sendiri, dan sebagainya untuk membuktikan hipotetis yang telah dibuat. Pada tahap ini secara tidak langsung menghubungkan masalah dengan pengetahuan sebelumnya.

d. Data Processing (pengolahan data)

Data yang telah dikumpulkan kemudian diolah, diklasifikasikan, atau dihitung untuk memperoleh jawaban apakah sesuai dengan hipotesis atau tidak.

e. Verification (pembuktian)

Melalui tahap ini, siswa melakukan pemeriksaan secara cermat dan teliti untuk membuktikan kebenaran hipotesis yang diterapkan sebelumnya, serta dihubungkan dengan hasil data processing.

f. Generalization (menarik kesimpulan/ generalisasi)

Pada tahap ini dilakukan penyimpulan yang dapat dijadikan prinsip umum dan berlaku untuk semua kejadian atau masalah yang sama dengan memperhatikan hasil verifikasi.

\subsection{Pembelajaran Konvensional}


Pembelajaran konvensional yang dimaksud penelitian ini adalah metode ekspositori. Menurut Ruseffendi (2006: 290) menyatakan bahwa tahapan-tahapan dalam metode ekspositori adalah guru berbicara pada awal pelajaran dengan menerangkan suatu konsep, siswa bertanya, guru memeriksa (mengecek) apakah siswa sudah mengerti atau belum, selanjutnya guru memberikan soal-soal aplikasi konsep itu dan meminta siswa untuk menyelesaikan soal-soal tersebut di papan atau di mejanya. Siswa mungkin bekerja secara individual atau bekerja sama dengan teman yang duduk di sampingnya, dan sedikit tanya jawab. Dan kegiatan terakhir adalah siswa mencatat materi yang telah dijelaskan.

\subsection{Pemahaman Konsep Matematis}

pemahaman konsep adalah suatu kemampuan menafsirkan, memperkirakan, mengerti dan memahami suatu konsep-konsep materi setelah dipelajari, serta mampu menangkap makna tentang materi yang telah dipelajari itu. Dengan demikian siswa memiliki kemampuan untuk menerjemahkan, menafsirkan, dan menyimpulkan suatu konsep matematika berdasarkan pembentukan pengetahuannya sendiri yang bukan hasil dari menghafal.

\section{METODE PENELITIAN}

Jenis penelitian yang digunakan dalam penelitian ini adalah eksperimen semu (quasi eksperiment). Dikatakan quasi eksperiment karena penelitian yang dilakukan melibatkan kelas kontrol dan peneliti tidak mungkin melakukan pengontrolan penuh terhadap variabel-variabel luar yang mempengaruhi pelaksanaan eksperimen. Kelas eksperimen adalah kelas yang diberi perlakuan pembelajaran menggunakan model discovery learning, sedangkan kelas kontrol adalah kelas yang diberi perlakuan pembelajaran menggunakan model pembelajaran konvensional.

\subsection{Desain Penelitian}

Format Post-test Only Control Design

Keterangan:

\begin{tabular}{ccc}
\hline $\mathrm{E}$ & $\mathrm{X}_{1}$ & $\mathrm{O}_{1}$ \\
\hline $\mathrm{K}$ & $\mathrm{X}_{2}$ & $\mathrm{O}_{2}$ \\
\hline
\end{tabular}

E : Kelompok Eksperimen

K : Kelompok Kontrol

$\mathrm{O}_{1} \quad$ : Kemampuan akhir / Post-test kelas eksperimen

$\mathrm{O}_{2} \quad$ : Kemampuan akhir / Post-test kelas kontrol

$\mathrm{X}_{1} \quad$ : Perlakuan pada kelas eksperimen dengan penggunaan model discovery learning

$\mathrm{X}_{2} \quad$ : Perlakuan pada kelas kontrol dengan penggunaan model 
pembelajaran konvensional

(Sugiyono, 2015: 112)

\section{HASIL DAN PEMBAHASAN}

\subsection{Hasil Penelitian}

Deskripsi Data Hasil Observasi Keterlaksanaan Pembelajaran

Hasil dari observasi dengan pedoman lembar observasi yang dilakukan observer digunakan untuk mengetahui keterlaksanaan pembelajaran pada kelas eksperimen yaitu model discovery learning dan model pembelajaran konvensional. Hasil dari observasi tersebut disajikan dalam bentuk tabel dibawah ini.

Tabel 4.1 Persentase Hasil Observasi Keterlaksanaan Pembelajaran

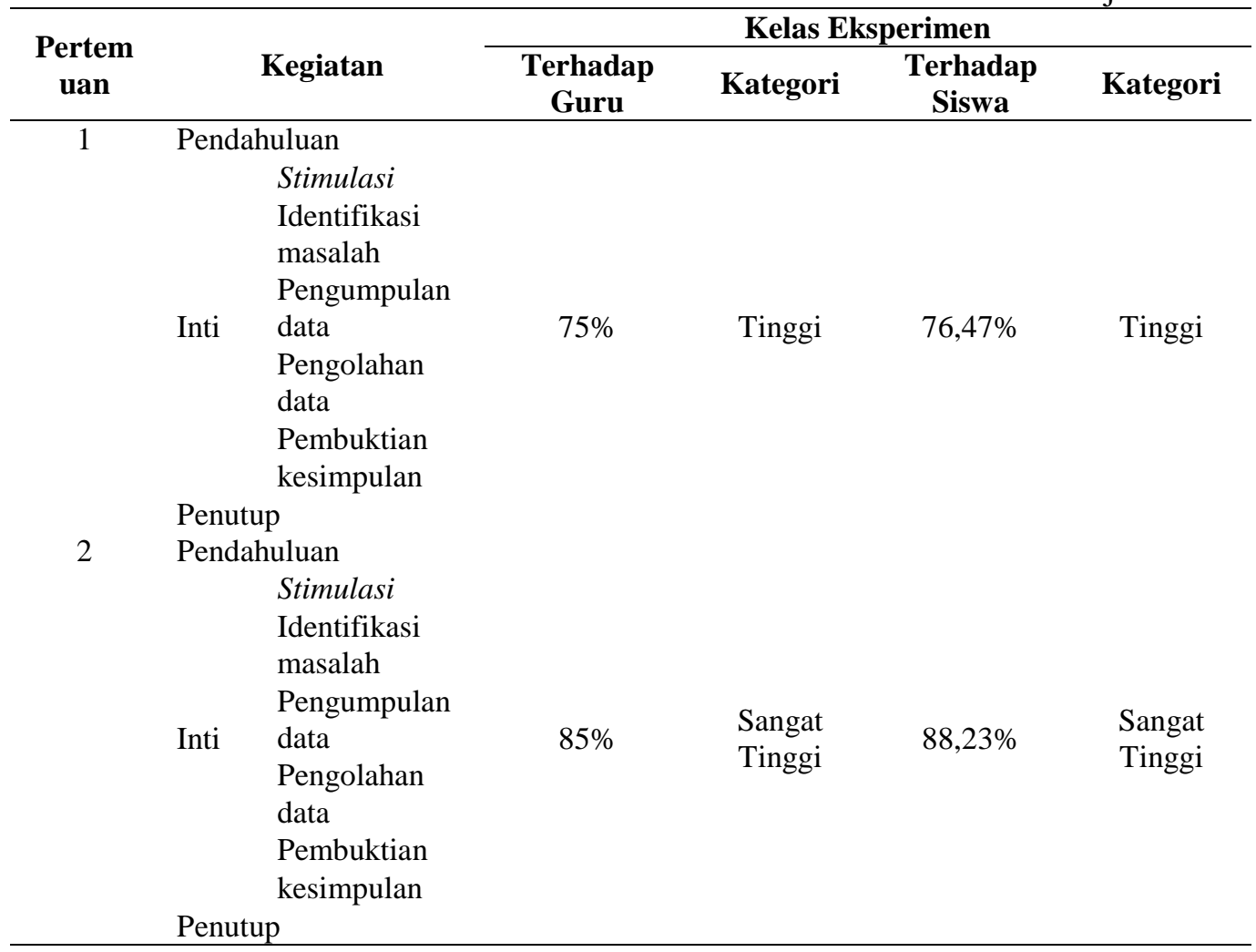

Tabel 4.2 Persentase Hasil Observasi Keterlaksanaan Pembelajaran

\begin{tabular}{cccccc}
\hline \multirow{2}{*}{$\begin{array}{c}\text { Pertem } \\
\text { uan }\end{array}$} & Kegiatan & $\begin{array}{c}\text { Terhadap } \\
\text { Guru }\end{array}$ & Kategori & $\begin{array}{c}\text { Terhadap } \\
\text { Siswa }\end{array}$ & Kategori \\
\cline { 3 - 6 } 1 & Pendahuluan & & Sangat & Sangat \\
& $\begin{array}{c}\text { Inti } \\
\text { Penutup } \\
\text { Pendahuluan }\end{array}$ & $86,67 \%$ & Tinggi & Tinggi \\
2 & Inti & & & $76,61 \%$ & Tinggi \\
& Penutup & & Tinggi & \\
\hline
\end{tabular}


Deskripsi Data Hasil Posttest Kelas Kontrol dan Kelas Eksperimen.

Setelah dilakukan pembelajaran (treatment) maka dilakukan pengambilan nilai posttest pada kelas kontrol dan eksperimen diperoleh deskripsi data sebagai berikut:

Tabel 4.3 Data Hasil Posttest Kelas Kontrol dan Eksperimen

\begin{tabular}{ccc}
\hline \multirow{2}{*}{ No } & \multicolumn{2}{c}{ Nilai } \\
\cline { 2 - 3 } & Kelas Eksperimen & Kelas Kontrol \\
\hline 1 & 100 & 80 \\
2 & 75 & 75 \\
3 & 50 & 80 \\
4 & 95 & 72,5 \\
5 & 90 & 72,5 \\
6 & 95 & 75 \\
7 & 85 & 75 \\
8 & 100 & 80 \\
9 & 75 & 77,5 \\
10 & 100 & 75 \\
11 & 72,5 & 80 \\
12 & 65 & 95 \\
13 & 100 & 90 \\
14 & 100 & 82,5 \\
15 & 72,5 & 75 \\
16 & 82,5 & 62,5 \\
17 & 75 & 75 \\
18 & 72,5 & 90 \\
19 & 80 & 80 \\
20 & 80 & 72,5 \\
21 & 77,5 & 75 \\
22 & 72,5 & 92,5 \\
23 & 90 & 90 \\
24 & 100 & 75 \\
25 & 80 & 90 \\
26 & 75 & 57,5 \\
\hline
\end{tabular}

Tabel 4.4 Data Hasil Posttest Pemahaman Konsep Matematis Siswa Tiap Indikator

\begin{tabular}{ccc}
\hline Indikator Pemahaman & \multicolumn{2}{c}{ Pencapaian Nilai Tiap Indkator } \\
\cline { 2 - 3 } Konsep & Kelas Eksperimen & Kelas Kontrol \\
\hline A & 76,92 & 43,27 \\
B & 90,38 & 86,54 \\
C & 75,00 & 79,67 \\
D & 92,79 & 84,13 \\
E & 87,82 & 85,9 \\
F & 76,92 & 79,49 \\
G & 68,59 & 65,38 \\
\hline
\end{tabular}

\section{Uji Hipotesis}

Uji Efektivitas pembelajaran matematika dengan model discovery learning

Setelah didapatkan nilai posttest maka dapat dilakukan uji t satu pihak untuk mengetahui efektivitas pembelajaran matematika dengan menggunakan discovery learning berikut hasilnya: 


$$
\begin{aligned}
& t_{\text {hitung }}=\frac{83,08-70}{\frac{13,1017}{\sqrt{26}}} \\
& t_{\text {hitung }}=\frac{13,08}{\frac{13,1017}{5,09902}} \\
& t_{\text {hitung }}=\frac{13,08}{2,56945452} \\
& t_{\text {hitung }}=5,09057
\end{aligned}
$$

Nilai $t_{\text {hitung }}$ adalah 5,09057 dimana 5,09057>2,05954. Maka $H_{0}$ ditolak dan $H_{1}$ diterima pada signifikansi $\alpha=0,05$, data nilai rata-rata posttest kelas eksperimen dengan menggunakan model discovery learning $>70$, sehingga model discovery learning efektif terhadap pemahaman konsep matematis siswa kelas XI IPS SMA Negeri 1 Gamping.

Uji Efektivitas pembelajaran matematika dengan model pembelajaran konvensional

Setelah didapatkan nilai posttest maka dapat dilakukan uji t satu pihak untuk mengetahui efektivitas pembelajaran matematika dengan menggunakan model pembelajaran konvensional berikut hasilnya:

$$
\begin{aligned}
& t_{\text {hitung }}=\frac{78,65-70}{\frac{8,7815}{\sqrt{26}}} \\
& t_{\text {hitung }}=\frac{8,65}{\frac{8,7815}{5,09902}} \\
& t_{\text {hitung }}=\frac{8,65}{1,72219368} \\
& t_{\text {hitung }}=5,02266
\end{aligned}
$$

Nilai $t_{\text {hitung }}$ adalah 5,02266 dimana 5,02266>2,05954. Maka $H_{0}$ ditolak dan $H_{1}$ diterima pada signifikansi $\alpha=0,05$, data nilai rata-rata posttest kelas kontrol dengan menggunakan model pembelajaran konvensional $>70$, sehingga model pembelajaran konvensional efektif terhadap pemahaman konsep matematis siswa kelas XI IPS SMA Negeri 1 Gamping.

Uji Efektivitas pembelajaran matematika dengan model discovery learning dibandingkan dengan model pembelajaran konvensional

Setelah didapatkan nilai posttest maka dapat dilakukan uji t satu pihak untuk mencari apakah 
pembelajaran matematika dengan menggunakan model discovery learning lebih efektif dibandingkan dengan model pembelajaran konvensional bila ditinjau dari pemahaman konsep matematis siswa, berikut hasilnya:

$$
\begin{aligned}
& t_{\text {hitung }}=\frac{83,08-78,65}{\sqrt{\frac{171,654+77,115}{26.26}}} \\
& t_{\text {hitung }}=\frac{4.43}{0,606631} \\
& \text { hitung }=7,30262
\end{aligned}
$$

Nilai $t_{\text {hitung }}$ adalah 7,30262 dimana 7,30262 >2,00856. Maka $H_{0}$ ditolak dan $H_{1}$ diterima pada signifikansi $\alpha=0,05$, artinya nilai rata-rata post-test pemahaman konsep matematis kelas model discovery learning lebih tinggi daripada kelas model pembelajaran konvensional. Sehingga model pembelajaran Discovery Learning lebih efektif dibandingkan dengan model pembelajaran konvensional bila ditinjau dari pemahaman konsep matematis siswa kelas XI IPS SMA Negeri 1 Gamping.

\subsection{Pembahasan}

Pembelajaran yang dilaksanakan di kelas eksperimen dengan menggunakan model discovery learning dan kelas kontrol dengan model pembelajaran konvensional yang masingmasing selama 2 kali pertemuan dan didampingi oleh satu observer. Rata-rata hasil observasi keterlaksanakaan pembelajaran terhadap guru pada kelas eksperimen sebesar $80 \%$ dengan kategori tinggi dan rata-rata hasil observasi keterlaksanaan pembelajaran terhadap guru pada kelas kontrol sebesar $83,33 \%$ dengan kategori sangat tinggi. Sedangkan rata-rata hasil observasi keterlaksanaan pembelajaran terhadap siswa pada kelas eksperimen sebesar 82,35\% dengan kategori sangat tinggi dan rata-rata hasil observasi keterlaksanaan pembelajaran terhadap siswa pada kelas kontrol sebesar 80,76\% dengan kategori sangat tinggi.

Setelah pembelajaran pada kelas eksperimen maupun kelas kontrol selesai, siswa diminta mengerjakan soal posttest untuk mengetahui hasil akhir pemahaman konsep siswa. Hasil pengujian dari nilai posttest di kelas eksperimen, nilai $t_{\text {hitung }}$ adalah 5,09057 dimana $5,09057>2,05954$. Maka $H_{0}$ ditolak dan $H_{1}$ diterima pada signifikansi $\alpha=0,05$. Data nilai rata-rata posttest kelas eksperimen dengan menggunakan model discovery learning $>70$, sehingga model discovery learning efektif terhadap pemahaman konsep matematis siswa kelas XI IPS SMA Negeri 1 Gamping. 
Model pembelajaran konvensional juga efektif terhadap pemahaman konsep siswa, dengan melihat nilai $t_{\text {hitung }}$ diperoleh nilai $t_{\text {hitung }}$ adalah 5,02266 dimana 5,02266 > 2,05954, sehingga $H_{0}$ ditolak dan $H_{1}$ diterima pada signifikansi $\alpha=0,05$. Data nilai rata-rata posttest kelas kontrol dengan menggunakan model pembelajaran konvensional $>70$, sehingga model pembelajaran konvensional efektif terhadap pemahaman konsep matematis siswa kelas XI IPS SMA Negeri 1 Gamping.

Dari uraian di atas, telah diketahui bahwa dalam pembelajaran yang menggunakan model discovery learning maupun model pembelajaran konvensional sama-sama efektif terhadap pemahaman konsep matematis siswa. Selanjutnya dalam pengujian efektivitas pembelajaran dengan menggunakan model discovery learning dibandingkan dengan pembelajaran model konvensional, dengan melihat $t_{\text {hitung }}$ diperoleh nilai $t_{\text {hitung }}$ adalah 7,30262 dimana 7,30262 2,00856. Maka $H_{0}$ ditolak dan $H_{1}$ diterima pada signifikansi $\alpha=0,05$, artinya model pembelajaran Discovery Learning lebih efektif dibandingkan dengan model pembelajaran konvensional bila ditinjau dari pemahaman konsep matematis siswa kelas XI IPS SMA Negeri 1 Gamping.

\section{KESIMPULAN}

1. Penggunaan model Discovery Learning efektif bila ditinjau dari pemahaman konsep matematis siswa dengan nilai $t_{\text {hitung }}$ adalah 5,09057 dimana $t_{\text {hitung }}>t_{\text {tabel }}=2,05954$.

2. Penggunaan model pembelajaran konvensional efektif bila ditinjau dari pemahaman konsep matematis siswa dengan $t_{\text {hitung }}$ adalah 5,02266 dimana $t_{\text {hitung }}>t_{\text {tabel }}=2,05954$.

3. Model pembelajaran Discovery Learning lebih efektif dibandingkan dengan model pembelajaran konvensional bila ditinjau dari pemahaman konsep matematis siswa kelas XI IPS SMA Negeri 1 Gamping. Hal ini juga terlihat dari hasil rata-rata posttest kelas eksperimen yaitu 83,08 lebih tinggi dari hasil nilai rata-rata kelas kontrol yaitu 78,65.

\section{Daftar Pustaka}

Cahyo, A. 2013. Panduan Aplikasi Teori-Teori Belajar Mengajar. Jakarta: PT. Diva Press.

Hosnan. 2014. Pendekatan Saintifik dan Kontekstual dalam Pembelajaran Abad 21. Bogor: Ghalia Indonesia.

Ruseffendi. 2006. Pengantar kepada membantu guru mengembangkan kompetensinya dalam pengajaran matematika. Bandung: Tarsito.

Sugiyono. 2015. Metode Penelitian Pendekatan Kuantitatif Kualitatif dan R\&D. Bandung: Alfabeta. 


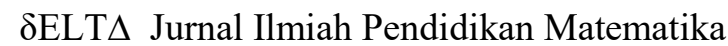

